\title{
A colaboração da Fonoaudiologia educacional em prol de um sistema de ensino
}

\section{igualitário}

The collaboration of educational speech therapy in favor of an egalitarian education system

La colaboración de la logopedia educativa a favor de un sistema educativo igualitario

Recebido: 22/12/2020 | Revisado: 24/12/2020 | Aceito: 28/12/2020 | Publicado: 02/01/2021

\author{
Poliana Carneiro Santos \\ ORCID: https://orcid.org/0000-0003-2991-1134 \\ Faculdade de Ensino Superior do Piauí, Brasil \\ E-mail: Policarneiro23@gmail.com \\ Mariana Fonseca Silva Nascimento \\ ORCID: https://orcid.org/0000-0001-7275-2808 \\ Faculdade de Ensino Superior do Piaú, Brasil \\ E-mail: fgamarianafonseca@ hotmail.com
}

\begin{abstract}
Resumo
A presente pesquisa possui como objetivo principal analisar a contribuição da fonoaudiologia por meio de seus profissionais no que se refere à inclusão de crianças com necessidades educacionais especiais em escola regular. Dentre os objetivos específicos ressaltam-se: Identificar de que modo atua os profissionais de fonoaudiologia na educação escolar regular; Demonstrar os principais instrumentos da fonoaudiologia em prol da inclusão escolar; Verificar os principais atores envolvidos na atuação fonoaudiológica.Para a fundamentação da pesquisa houve a necessidade de realizar uma revisão bibliográfica, analisando diversas teorias sobre as formas que a fonoaudiologia pode contribuir em prol do melhor desenvolvimento na educação regular de alunos que apresentam necessidades especiais. As fontes de pesquisa foram artigos científicos, monografias, dissertações, livros e consultas em sítios eletrônicos (internet), ressaltando-se Scielo, Pubmed e Medline.Concluiu-se pela presente pesquisa que a Fonoaudiologia é de suma importância na contribuição de uma educação caracterizada pela inclusão, juntamente a equipes multidisciplinares, como pedagogos, por exemplo, objetivando sempre uma vida mais saudável do corpo discente. Constatou-se ainda na pesquisa, posteriormente ao estudo dos referenciais teóricos, que todas as pesquisas descrevem a inclusão de um modo mais alicerçado na teoria, demonstrando como deve correr a atuação do fonoaudiólogo no processo de inclusão educacional, demonstrando regras necessárias para a sua eficácia, quais os profissionais que devem integrar uma equipe multidisciplinar, no entanto não retratam a realidade da prática de inclusão educacional, não mostrando como o processo de inclusão tem ocorrido realmente, sendo evidenciado que relatos de casos ainda são bastante escassos sobre a temática. Assim, considera importante que sejam elaboradas novas pesquisas demonstrando a prática na educação inclusiva.
\end{abstract}

Palavras-chave: Fonoaudiologia; Necessidades educacionais especiais; Inclusão.

\begin{abstract}
The present research has as main objective to analyze the contribution of speech therapy through its professionals regarding the inclusion of children with special educational needs in regular schools. Among the specific objectives, the following stand out: Analyze how speech therapy professionals work in regular school education; Identify the main instruments of speech therapy for school inclusion; to verify the main actorsinvolved in speech therapy. To support the research, there was a need to carry out a bibliographic review, analyzing several theories about the ways that speech therapy can contribute to the better development in the regular education of students with special needs. The research sources were scientific articles, monographs, dissertations, books and consultations on electronic sites (internet). It was concluded by the present research that Speech Therapy is extremely important in the contribution of an education characterized by inclusion, together with multidisciplinary teams, such as pedagogues, for example, always aiming at a healthier life. It was also found in the research, after the study of theoretical frameworks, that all research describes the inclusion in a more grounded way in theory, demonstrating how the performance of the speech therapist in the educational inclusion process should run, demonstrating necessary rules for its effectiveness, which professionals should be part of a multidisciplinary team, however, do not portray the reality of the practice of educational inclusion, not showing how the inclusion process has really occurred, showing that case reports are still very scarce on the subject. Thus, it considers it important that new research be developed demonstrating the practice in inclusive education.
\end{abstract}

Keywords: Speech therapy; Special educational needs; Inclusion. 


\begin{abstract}
Resumen
La presente investigación tiene como principal objetivo analizar la contribución de la Fonoaudiologia a través de sus profesionales en cuanto a la inclusión de niños con necesidades educativas especiales en las escuelas regulares. Entre los objetivos específicos, se destacan los siguientes: Identificar cómo trabajan los profesionales de logopedia en la educación escolar regular; Demostrar los principales instrumentos de la logopedia para la inclusión escolar; Verificar los principales actores involucrados en las actividades de logopedia Para apoyar la investigación fue necesario realizar una revisión bibliográfica, analizando varias teorías sobre las formas en que la logopedia puede contribuir al mejor desarrollo en la educación regular de los estudiantes con necesidades especiales. Las fuentes de investigación fueron artículos científicos, monografías, disertaciones, libros y consultas en sitios electrónicos (internet), destacando Scielo, Pubmed y Medline. Se concluyó con esta investigación que la logopedia es de suma importancia en el aporte de una educación caracterizada de inclusión, junto a equipos multidisciplinares, como los pedagogos, por ejemplo, siempre con el objetivo de una vida más saludable para el alumnado. También se encontró en la investigación, luego del estudio de los marcos teóricos, que toda investigación describe la inclusión de una manera más fundamentada en la teoría, demostrando cómo debe correr la actuación del logopeda en el proceso de inclusión educativa, demostrando las reglas necesarias para su efectividad, cuyos profesionales deben formar parte de un equipo multidisciplinario, sin embargo, no retratan la realidad de la práctica de la inclusión educativa, al no mostrar cómo ha ocurrido realmente el proceso de inclusión, mostrando que los reportes de casos aún son muy escasos sobre el tema. Por ello, considera importante que se desarrollen nuevas investigaciones que demuestren la práctica en educación inclusiva.
\end{abstract}

Palabras clave: Terapia del habla; Necesidades educativas especiales; Inclusión.

\title{
1. Introdução
}

Conforme o Plano Nacional de Educação (PNE), o Brasil deve incluir todos os estudantes de 4 a 17 anos na escola. Os alunos com necessidades especiais devem ser matriculados preferencialmente em classes comuns. Para isso, o Brasil deve garantir todo o sistema educacional inclusivo, salas de recursos multifuncionais, classes, escolas ou serviços especializados, públicos ou conveniados.

Para a implementação do Decreto no 6.571/2008, os sistemas de ensino devem matricular os alunos com deficiência, transtornos globais do desenvolvimento e altas habilidades/superdotação nas classes comuns do ensino regular e no Atendimento Educacional Especializado (AEE), ofertado em salas de recursos multifuncionais ou em centros de Atendimento Educacional Especializado da rede pública ou de instituições comunitárias, confessionais ou filantrópicas sem fins lucrativos.

Conforme o Ministério da Educação no ano de 2014 eram 886.815 os alunos com deficiência, altas habilidades e transtornos globais do desenvolvimento matriculados nas escolas brasileiras. Esse número tem aumentado ano a ano. Em 2018, chegou a cerca de 1,2 milhão. Entre 2017 e 2018, houve aumento de aproximadamente 10,8\% nas matrículas.

A educação é de suma importância para o ser humano, proporcionando desenvolvimento e aprendizagem, a qual não se restringe apenas as paredes de uma sala de aula, mas se estende por toda a vida, sendo realizada não somente por meio da atuação de professores, mas pelo convívio em sociedade (Freire, 1997).

Devido a grande importância do processo educacional na escola regular, o ambiente escolar deve procurar todos os modos de realizar uma adaptação para o maior atendimento possível das principais necessidades do seu corpo discente, independentemente de seres alunos que apresentem alguma necessidade especial ou não.

Para um processo de ensino-aprendizagem seja adequado deve haver uma preocupação com a linguagem, a qual é a representação interna do mundo no qual o aluno está inserido. A linguagem juntamente com as outras formas de comunicação possuem como finalidade possibilitar que os alunos sejam capazes de realizarem a codificação e interiorização de conteúdos e informações repassadas em sala de aula, para a posteriori serem capazes de se socializarem e compreenderem outras pessoas que utilizem linguagem semelhante (Siqueira, 2012).

Nesse contexto se faz de suma importância o papel do fonoaudiólogo educacional, o profissional da área da saúde, de atuação marcada pela autonomia e independência, exercendo suas competências na esfera pública e privada, procurando desenvolver ações de saúde coletiva, implementando, coordenando, adaptando e gerenciando vários programas e campanhas de promoção e de prevenção em saúde (Teberosky, 2018). 
Os profissionais da fonoaudiologia educacionais são capazes de proporcionar benefícios em prol de melhorias do desenvolvimento dos alunos que possuem necessidade especial na educação regular, pois para uma sociedade ser inclusiva deve estar disposta a atender a todos, sem distinção de sexo, faixa etária, convicção religiosa, orientação sexual ou deficiência, devendo haver o fomento da participação, objetivando que todos os seres humanos possam desenvolver os seus potenciais nas mais diversas áreas de atuação (Ribas, 2015).

A problemática da pesquisa consiste no seguinte questionamento: de que forma a fonoaudiologia educacional pode contribuir no processo de uma educação inclusiva na rede regular de ensino?

A presente pesquisa possui como objetivo geral analisar as principais contribuições da fonoaudiologia na inclusão de crianças com necessidades educacionais especiais em escola regular. Dentre os objetivos específicos ressaltam-se: Analisar de que modo atua os profissionais de fonoaudiologia na educação escolar regular: Identificar os principais instrumentos da fonoaudiologia em prol da inclusão escolar; verificar os principais atores envolvidos na atuação fonoaudiológica.

A pesquisa é pertinente, sendo extremamente importante o atendimento do maior número possível de alunos que apresentem alguma necessidade especial no tratamento da escola regular, oferecendo, por exemplo, o devido acompanhamento de profissionais da fonoaudiologia para aqueles que apresentam dificuldades de comunicação. Desse modo o Assim, o fonoaudiólogo em parceria com outros profissionais da educação, como pedagogos podem realizar a construção de um ambiente educacional amplamente favorável, com a finalidade de desenvolvimento das habilidades comunicativas e das potencialidades dos alunos promovendo uma espécie de saúde escolar.

\section{Referencial Teórico}

\subsection{Políticas de educação inclusiva no Brasil}

O movimento em nível internacional em prol de uma educação pautada em aspectos inclusivos é uma ação política, cultural, social e pedagógica, com a finalidade precípua de defender o direito de todos os alunos de permanecerem juntos, aprendendo e participando, sem nenhuma forma de discriminação. A educação inclusiva pode ser entendida como um paradigma da educação alicerçado na ideia de direitos humanos, que associa igualdade e diferença como valores indissociáveis, avançando em relação à ideia de equidade formal ao contextualizar as circunstâncias históricas da produção da exclusão, tanto no âmbito da escola como fora dela.

A Lei de Diretrizes e Bases da Educação Nacional preceitua sobre uma educação alicerçada em um processo de inclusão escolar, e em seu artigo 59, preconiza-se que os sistemas de ensino deverão assegurar aos estudantes, currículo, métodos, recursos e organização específicos para atender às suas necessidades; além de assegurar a terminalidade específica àqueles que não atingiram o nível exigido para a conclusão do ensino fundamental, em virtude de suas deficiências assegurando a aceleração de estudos aos superdotados para conclusão do programa escolar.

A LDB também define, em seu art. 24, dentre as normas para a organização da educação básica, a possibilidade de avanço nos cursos e nas séries mediante verificação do aprendizado e oportunidades educacionais apropriadas, consideradas as características do alunado, seus interesses, condições de vida e de trabalho, mediante cursos e exames.

No ano de 2001 surge As Diretrizes Nacionais para a Educação Especial na Educação Básica (Resolução CNE/CEB $\left.n^{\circ} 2 / 2001\right)$ que preceitua em seu artigo $2^{\circ}$, que: “Os sistemas de ensino devem matricular todos os estudantes, cabendo às escolas organizarem-se para o atendimento aos educandos com necessidades educacionais especiais", devendo garantir as condições necessárias para uma educação de qualidade para todos.

No ano de 2001 ainda é elaborado o Plano Nacional de Educação -PNE (Lei nº 10.172/2001), o qual preceitua que “o grande avanço que a década da educação deveria produzir seria a construção de uma escola inclusiva que garanta o atendimento à diversidade humana". 
No ano de 2002 é promulgada a Lei $n^{\circ}$ 10.436, a qual reconhece a Língua Brasileira de Sinais-Libras com um meio legal de comunicação e forma de expressão, determinando, desse modo, que sejam asseguradas formas institucionalizadas de apoiar seu uso e difusão, assim como da inclusão da disciplina de Libras como parte integrante do currículo nos cursos de formação de professores e de fonoaudiologia.

Já no ano de 2003 é implementado pelo Ministério da Educação o Programa Educação Inclusiva, destacando uma serie de fatores como o direito à diversidade, com vistas a apoiar a transformação dos sistemas de ensino em sistemas educacionais inclusivos, promovendo um amplo processo de formação de gestores e educadores nos municípios brasileiros para a garantia do direito de acesso de todos à escolarização, à oferta do atendimento educacional especializado e à garantia da acessibilidade.

Em 2006 ocorre a Convenção sobre os Direitos das Pessoas com Deficiência, aprovada pela Organização das Nações Unidas e ratificada Emenda Constitucional por força do Decreto Legislativo n 186/2008 e do Decreto Executivo ${ }^{\circ}$ 6949/2009, estabelecendo que os Estados-Partes devem assegurar um sistema de educação inclusiva em todos os níveis de ensino, em ambientes que maximizem o desenvolvimento acadêmico e social compatível com a meta da plena participação e inclusão, adotando medidas para garantir que, consoante diploma legislativo do aludido Decreto:

As pessoas com deficiência não sejam excluídas do sistema educacional geral sob alegação de deficiência e que as crianças com deficiência não sejam excluídas do ensino fundamental gratuito e compulsório, sob alegação de deficiência; b) As pessoas com deficiência possam ter acesso ao ensino fundamental inclusivo, de qualidade e gratuito, em igualdade de condições com as demais pessoas na comunidade em que vivem (Art.24). O Decreto $\mathrm{n}^{\circ}$ 6571/2008, incorporado pelo Decreto $n^{\circ} 7611 / 2011$, institui a política pública de financiamento no âmbito do Fundo de Manutenção e Desenvolvimento da Educação Básica e de Valorização dos Profissionais da Educação -FUNDEB, estabelecendo o duplo cômputo das matrículas dos estudantes com deficiência, transtornos globais do desenvolvimento e altas habilidades/superdotação. Visando ao desenvolvimento inclusivo dos sistemas públicos de ensino, este Decreto também define o atendimento educacional especializado complementar ou suplementar à escolarização e os demais serviços da educação especial, além de outras medidas de apoio à inclusão escolar (Brasil, 2009)

A Constituição Federal de 1988 destaca entre os seus objetivos a construção de uma sociedade livre, justa e solidária, garantia de desenvolvimento nacional, erradicação da pobreza e da marginalização, redução das desigualdades sociais e regionais e a promoção do bem de todos, sem preconceitos de origem, raça, sexo, cor, idade, e qualquer outra forma de discriminação.

No ano de 2008, foi lançada a política nacional de educação especial na perspectiva da educação inclusiva e aprovada no território da República Federativa do Brasil por meio de emenda constitucional a convenção da ONU sobre os direitos das pessoas com deficiência. Conforme essa convenção deve, obrigatoriamente, ser assegurados sistemas educacionais inclusivos em todos os níveis e modalidades da educação nacional, desde a educação infantil até o nível superior. O Decreto de ${ }^{\circ}$ 6.571, de 17 de setembro de 2008, dispõe, de forma expressa, sobre o atendimento educacional especializado.

Mesmo com um ordenamento jurídico vasto ainda se observa a dificuldade de alunos com necessidades especiais se adequarem a educação regular de ensino, pois é evidente no Brasil que muitas escolas não estão adaptadas para receberem alunos que necessitam de uma atenção especial.

\subsection{A relação entre Fonoaudiologia $x$ educação}

Conforme a Lei 6965, art. $1^{\text {o }}$, de 9 de dezembro de 1981 o Fonoaudiólogo é aquele o profissional que possui graduação plena e que atua em pesquisa, prevenção, avaliação e terapia na área da comunicação oral e escrita, voz e audição, assim como em aperfeiçoamento dos padrões de fala. 
A Fonoaudiologia Educacional é uma área de especialização da fonoaudiologia voltada à promoção da Educação, em todos os níveis e/ou modalidades de ensino. O fonoaudiólogo educacional pode atuar em Secretarias Municipais e Estaduais de Educação, em escolas da rede pública e do setor privado, em sistemas de ensino, em empresas de consultoria e assessoria. Para tanto, deve conhecer as políticas de educação definida em âmbito federal, estadual e municipal, bem como os programas, projetos e ações relacionadas ao processo de ensino e aprendizagem.

Já no capítulo II, artigo $3^{\circ}$, da referida há o estabelecimento das principais competências do fonoaudiólogo, ressaltando-se a funções de desenvolver trabalho de prevenção no que se refere à área de comunicação escrita e oral, voz e audição, participar da equipe de orientação e planejamento escolar, inserindo aspectos preventivos ligados a assuntos fonoaudiológico.

O fonoaudiólogo, em sua atuação junto à Educação, defronta-se com vários tipos de demandas, predominando muitas vezes aquelas ligadas a alunos que apresentam algum tipo de dificuldade ou transtorno, como é o caso dos escolares que estão inseridos nos programas de Educação Especial. Embora essas crianças necessitem de uma atenção diferenciada por parte dos fonoaudiólogos que trabalham junto às escolas, uma visão verdadeiramente educacional deve ir além da intervenção em casos individuais e ultrapassar a perspectiva de prevenção e promoção de saúde entre os escolares. Neste sentido, o papel primordial do fonoaudiólogo educacional deve ser o de colaborar com a construção de projetos e ações educacionais, voltados para toda a população de estudantes, que tenham como foco o desenvolvimento de competências, principalmente cognitivas, linguísticas e sociais, fundamentais para garantir condições favoráveis de aprendizagem e alcance das metas estabelecidas para cada etapa da escolaridade (Jaime zorzi alfabetização em foco)

Na construção de sua história, a Fonoaudiologia sempre estabeleceu vínculo estreito com a área da Educação. No entanto, sua atuação consolidou-se na área da saúde. Atualmente a Fonoaudiologia, assim como outras ciências da saúde, tem incorporado as propostas e conceitos relacionados à promoção de saúde, que incentiva o protagonismo e a autonomia do sujeito e da coletividade para agir em benefício de sua qualidade de vida. Inserido no contexto educacional, o desafio do fonoaudiólogo é colaborar, por meio do seu conhecimento, para o processo educativo.

\subsection{Atribuições do Fonoaudiólogo em prol da educação inclusiva}

O profissional da fonoaudiologia no ambiente escolar é um agente potencializador do desenvolvimento humano, prestando vários serviços, como consultoria, assessoria, técnico-administrativos e pesquisas. Objetiva detectar as dificuldades dos alunos, orientar os professores e toda a equipe da escola, além dos pais, e participar da criação, e implantação de programas educacionais em prol de inclusão de alunos com necessidades especiais, sempre buscando estabelecer parcerias com áreas afins. (Calheta, 2015).

O fonoaudiólogo na educação irá desenvolver um papel de máxima valorização da figura do professor em sala de aula, como elemento capaz de ajudar o aluno a desenvolver e aperfeiçoar sua comunicação verbal pela linguagem oral e escrita, principalmente os que apresentam dificuldade acentuada de aprendizagem; Deficientes Auditivos; Deficientes visuais; Deficiências múltiplas; Síndromes; Disfunção Neuromotora; Deficiência mental e Autismo (Ferreira, 2011).

Segundo Carvalho et al1, Fernandes e Crenitte2, fonoaudiólogo e professor precisam trabalhar juntos numa relação de troca, já que cada um tem seu papel definido e experiência dentro do imenso universo de ações que é a educação. A experiência da atuação do fonoaudiólogo associada à do professor, com base na integração de conhecimentos só têm a contribuir para o desenvolvimento dos alunos.

O fonoaudiólogo realizar também orientações em saúde vocal com objetivo de promover a saúde vocal dos docentes atuando na promoção da saúde vocal e prevenção das disfonias por meio de oficinas com orientações vocais e treinamentos para o uso adequado da voz criando condições para que os professores possam exercer suas atividades em sala de aula . 
Por meio de uma equipe interdisciplinar, na qual atuam psicólogos, fisioterapeutas, terapeutas ocupacionais e fonoaudiólogos, é possível que sejam elaborados programas direcionados aos alunos com necessidades especiais, objetivando o desenvolvimento de aspectos relacionados com a comunicação e com a linguagem a fim de que o estudante consiga ser capaz de exercer sua cidadania por meio de uma inclusão social que ocorra de fato.

O fonoaudiólogo educacional deve permeiar as suas ações realizadas no seio da escola regular, incluindo a família, o aluno e os professores, em um processo de despatologização, devolvendo a cada um seu papel no processo educacional. Esse caráter é diferente do clínico, não havendo enfoque na patologia e atendimento individual, mas o trabalho em grupos, buscando as adaptações, como por exemplo nos currículos escolares, em prol da inclusão, não se referindo mais a paciente, mas em participante ativo que ajudar a propor as direções do processo.

Estudos relativos à comunicação e inclusão de crianças com alterações de linguagem de origem neurológica necessitam, no entanto, de maior atenção, particularmente no âmbito da Fonoaudiologia, a qual pode contribuir nos aspectos de comunicação e de alimentação, assim como no processo de inclusão de alunos especiais na educação escolar regular (Garcez, 2019).

Não tratar o estudante como um doente é uma das melhores formas de realizar o processo de inclusão do aluno na educação regular, devendo ser identificado o que está dificultando o aprendizado e posteriormente utilizar métodos para que esse integrante do corpo discente seja capaz de interagir socialmente de de um modo adequado e eficiente, evitando uma maior desigualdade no ambiente familiar.

A fonoaudiologia pode ser considerada uma auxiliar para a educação escolar, por meio de parcerias em prol de refletir sobre os referenciais de linguagem para as práticas do processo de ensino-aprendizagem, constatando-se isso a partir de revisões bibliográfica e estudos de caso, como um estudo que foi realizado com aluno com Síndrome de Down no seu processo de escolarização. Os resultados demonstraram que com a colaboração de vários grupos, com a participação da fonoaudiologia, familiares e professores, a criança, favoreceu fortemente o seu desenvolvimento em situações de comunicação em um ambiente acolhedor da diversidade, fundamental em um processo de inclusão, dependente da participação de diferentes atores sociais (Maia, 2011).

Salienta-se que são diversas as contribuições dos profissionais da fonoaudiologia em prol da inclusão de alunos com necessidades especiais. Dentre as contribuições ressaltam-se o fato de o fonoaudiólogo possuir a competência de proporcionar uma série de condições favoráveis e eficazes para a otimização das capacidades dos alunos de forma individual. Neste contexto de inclusão e integração, a comunicação assume grande importância, uma vez que, quanto mais efetiva, maiores são as chances de inserção do aluno com necessidades especiais no contexto escolar (Alves, 2013).

O profissional da fonoaudiologia é capaz de contribuir significativamente com vários subsídios e propostas de recursos que são facilitadores do desenvolvimento da linguagem, principalmente para os alunos que possuam alguma necessidade especial, respeitando-se, desse modo, a individualidade de cada estudante. Desse modo, verifica-se, as várias possibilidades de formas de atuação do fonoaudiólogo em prol do processo de inclusão de alunos com necessidades educacionais especiais, tanto em escolas especiais, como também em escolas regulares de ensino (Reis, 2012)

O papel das várias modalidades de comunicação na inclusão escolar é extremamente importante no que se relaciona com as competências do profissional de fonoaudiologia com estudantes que possuam alguma espécie de necessidade especial, cabendo ao fonoaudiólogo realizar a atuação especialmente em principalmente nas áreas referentes a linguagem, tanto oral, como a linguagem escrita, com a motricidade orofacial, com a voz e também com a audição. Esta parceria pode proporcionar projetos pedagógicos que levem em consideração as singularidades e dificuldades de cada aluno, favorecendo o processo de interação social com outros alunos, e consequentemente realizando uma maior inclusão educacional. o aumento da capacidade 
de comunicação amplia a chance de aceitação dentro da sala de aula, independentemente de sua condição especial. (Martins, 2012).

Mesmo, sendo evidenciada a grande contribuição dos fonoaudiólogos no processo educacional há a necessidade de identificar por meio de uma equipe multidisciplinar as principais dificuldades de alunos da rede regular de ensino, pois somente, desse modo, há a possibilidade de ser realizado um direcionamento mais efetivo na atuação dos profissionais da fonoaudiologia, o qual poderá contribuir e prol do favorecimento do processo ensino-aprendizagem, contribuindo para uma maior socialização, assim como uma melhor qualidade de vida de alunos especiais (Monteiro, 2014).

Conforme a citação infere-se que os profissionais da fonoaudiologia podem proporcionar como contribuição para o processo de inclusão de alunos com necessidades especiais inserido na educação regular a identificação das principais dificuldades que afetam o processo de ensino aprendizagem, em especial no que se refere a aspectos linguísticos. Identificando precocemente essas falhas dos alunos poderá haver de um modo mais significativo a devida correção e a integração do aluno com necessidade especial.

Gertel (2011, p. 959) discorre sobre a contribuição dos profissionais da fonoaudiologia no processo de inclusão escolar:

O fonoaudiólogo pode e deve contribuir para a formação continuada de professores dos sistemas de educação regular e especial, de modo que a Escola possa ser compreendida como um espaço onde todos os que nela se inserem têm um potencial e um papel a desenvolver. Assim, incluir alunos com necessidades especiais deixa de ser visto como resultado de prática específica ou atendimento individualizado somente; ao contrário, passa a ser meta daqueles que acreditam que todos os alunos têm limites que devem ser respeitados.

O trabalho dos profissionais de fonoaudiologia na Educação regular caminha com o objetivo de realizar a construção, em parceria, prática mais significativa do processo de ensino e aprendizagem, buscando, além de ampliar seus parâmetros ajudar a decidir a adaptação do conteúdo pedagógico a ser trabalhado com cada aluno, principalmente no que se refere aos alunos que apresentem algum tipo de necessidades especiais. Somente adequando o currículo conforme observação de fonoaudiólogos é possível lograr êxito mais significativo em prol da inclusão escolar (Rios, 2011).

Umas das maiores contribuições da fonoaudiologia reside no fato de procurar continuamente realizar a adaptação do ambiente escolar em prol de um espaço que possibilite a redução das desigualdades entre os alunos, pois estudantes que possuem necessidades especiais devem ser tratados de modo que não fiquem excluídos do processo de ensino-aprendizagem.

\section{Metodologia}

No que se refere a metodologia a pesquisa trata-se de um estudo de revisão de literatura, fundamentada por meio das bases de dados: MEDLINE, SCIELO PUBMED e GOOGLE ACADÊMICO. A revisão da literatura, também chamada "revisão bibliográfica", visa a demonstrar o estágio atual da contribuição acadêmica em torno de um determinado assunto. Ela proporciona uma visão abrangente de pesquisas e contribuições anteriores, conduzindo ao ponto necessário para investigações futuras e desenvolvimento de estudos posteriores.

Inicialmente foi realizada a busca ativa das palavras-chave no portal de Descritores em Ciências da Saúde (DeCS). Com base no tema da contribuição da fonoaudiologia na inclusão de crianças com necessidades educacionais especiais em escola regular.

Foram analisados 22 artigos, por meio dos seguintes descritores: Educação inclusiva; fonoaudiologia, educação escolar regular. Posteriormente, foram analisados os artigos que mais interessavam no embasamento da pesquisa, usando os critérios de inclusão, ressaltando-se análise do artigo e sua contribuição sobre a temática da pesquisa, por meio da análise do 
resumo e da atualidade do estudo, assim como de exclusão, baseados na pergunta que norteia a revisão, mensuração dos desfechos de interesse, critério metodológico, idioma, tipo de estudo, tempo de busca, por meio de artigos publicados no período entre os anos de 2010 e 2020, disponibilizados na íntegra. Dos 18 artigos disponibilizados, foram excluídos 8 com base na análise do resumo, artigos repetidos e metodologia incompleta, restando uma amostra final de 10 artigos, os quais fundamentaram a pesquisa.

O critério de exclusão da pesquisa pautou-se nas contribuições da fonoaudiologia na inclusão de crianças com necessidades educacionais especiais em escola regular, sendo excluídas fontes que abordavam sobre as pessoas em geral que se encontram fora do ambiente escolar. Os estudos incluídos na revisão bibliográfica foram apresentados por meio da elaboração de um quadro, contendo o ano de publicação, periódicos, banco de dados e o tipo de pesquisa para uma melhor visualização e compreensão sobre o tema.

Considerando como método a revisão sistemática e considerando os descritores já mencionados, foram encontrados 22 artigos nas bases de dados SCIELO (Scientific Eletronic Library On line), LILACS (Literatura Latino Americana e do Caribe em Ciências da Saúde) e PubMed. Os artigos apresentados em mais de uma base de dados foram contabilizados apenas uma vez (Figura 1).

Figura 1: Quantidade de artigos conforme a base de dados.

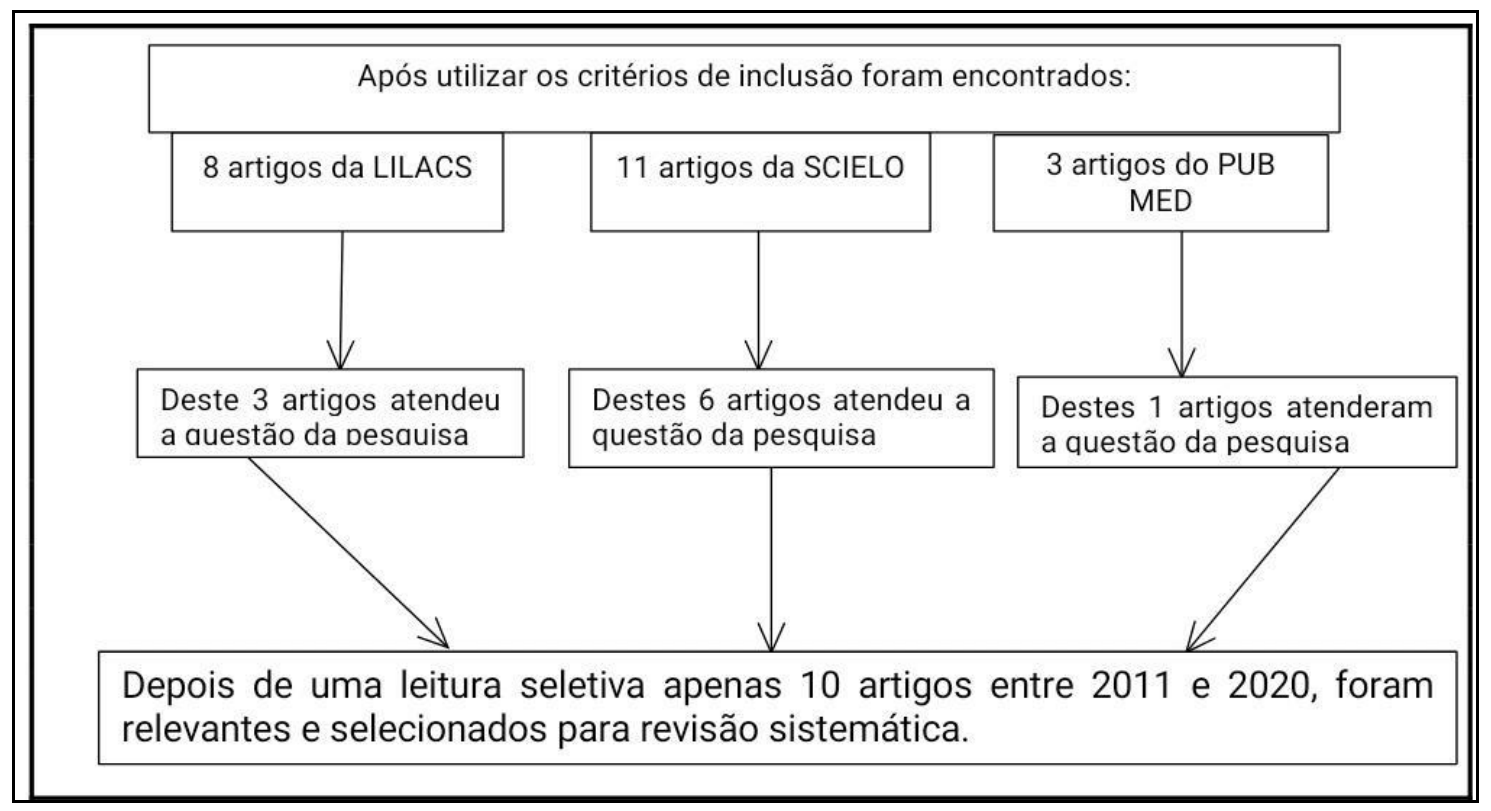

Fonte: Autor (2020).

Posteriormente a seleção dos artigos utilizados na presente pesquisa houve a necessidade da elaboração de um quadro no qual são inseridos o autor, o local de publicação, o tipo de metodologia e os resultados presentes nas fontes consultadas. 


\section{Resultados e Discussão}

Após analisar as diversas teorias, presentes em artigos científicos, monografias, dissertações, livros e consultas em sítios eletrônicos, analisando principalmente revistas científicas, referente as principais contribuição da fonoaudiologia para a inclusão educacional de alunos especiais chegou-se aos principais resultados.

O Quadro de número 1 demonstra de modo objetivo, conforme se evidenciou na pesquisa as principais contribuições da fonoaudiologia para a inclusão educacional de alunos especiais.

Quadro 1: Benefícios da fonoaudiologia no processo de inclusão escolar.

\begin{tabular}{|c|c|c|c|}
\hline Autor/Título & Base De Dados & Amostras & Conclusão \\
\hline Monteiro (2014) & Scielo & Pesquisa Qualitativa & $\begin{array}{l}\text { Contribuição no favorecimento } \\
\text { do processo ensino- } \\
\text { aprendizagem, contribuindo para } \\
\text { uma maior socialização e melhor } \\
\text { qualidade de vida de alunos } \\
\text { especiais. }\end{array}$ \\
\hline Martins (2012) & Scielo & Pesquisa Qualitativa & $\begin{array}{l}\text { Atuação nas áreas referentes a } \\
\text { linguagem oral e escrita, } \\
\text { motricidade orofacial, voz e } \\
\text { audição } \\
\text { Favorecimento do processo de } \\
\text { interação social de alunos que } \\
\text { necessitam de atenção especial. }\end{array}$ \\
\hline Calheta (2015) & Scielo & Pesquisa Qualitativa & $\begin{array}{l}\text { Observar e detectar as } \\
\text { dificuldades dos alunos, } \\
\text { orientando professores e toda a } \\
\text { equipe da escola, além dos pais, e } \\
\text { participar da criação, elaboração e } \\
\text { implantação de programas } \\
\text { educacionais em prol de inclusão } \\
\text { de alunos com necessidades } \\
\text { especiais. }\end{array}$ \\
\hline Ferreira (2011) & Scielo & Pesquisa Qualitativa & $\begin{array}{l}\text { Desenvolver um papel de máxima } \\
\text { valorização da figura do professor } \\
\text { em sala de aula, como um } \\
\text { elemento capaz de ajudar o aluno } \\
\text { com necessidade especial a } \\
\text { desenvolver e aperfeiçoar sua } \\
\text { comunicação verbal pela } \\
\text { linguagem oral e escrita. }\end{array}$ \\
\hline Reis (2012) & Scielo & Pesquisa Qualitativa & $\begin{array}{l}\text { Subsídios e propostas de recursos } \\
\text { que são facilitadores do } \\
\text { desenvolvimento da linguagem }\end{array}$ \\
\hline Garcez (2019) & Scielo & Pesquisa Qualitativa & $\begin{array}{l}\text { Caráter terapêutico educacional } \\
\text { que deve sempre permear as } \\
\text { ações realizadas no seio da escola } \\
\text { regular, em um processo } \\
\text { caracterizado pela } \\
\text { despatologização }\end{array}$ \\
\hline
\end{tabular}




\begin{tabular}{|c|c|c|c|}
\hline & & & $\begin{array}{l}\text { Contribui na comunicação e na } \\
\text { alimentação dos alunos que } \\
\text { apresentem necessidade especial }\end{array}$ \\
\hline Maia (2011) & pubmed & Estudo de caso & $\begin{array}{l}\text { Favorecimento do } \\
\text { desenvolvimento de aluno com } \\
\text { Síndrome de Down em situações } \\
\text { relacionadas com a comunicação }\end{array}$ \\
\hline Alves (2013) & Lilacs & Pesquisa qualitativa & $\begin{array}{l}\text { Proporcionar condições } \\
\text { favoráveis e eficazes para a } \\
\text { otimização das capacidades dos } \\
\text { alunos de forma individual. }\end{array}$ \\
\hline Rios (2011) & Lilacs & Estudo de caso & $\begin{array}{l}\text { Decidir a adaptação do conteúdo } \\
\text { pedagógico a ser trabalhado com } \\
\text { cada aluno, principalmente no } \\
\text { que se refere aos alunos que } \\
\text { apresentem algum tipo de } \\
\text { necessidades especiais, pois } \\
\text { somente adequando o currículo } \\
\text { conforme observação de } \\
\text { fonoaudiólogos é possível lograr } \\
\text { êxito mais significativos em prol } \\
\text { da inclusão escolar }\end{array}$ \\
\hline Gertel (2011) & Lilacs & Estudo de caso & $\begin{array}{l}\text { o fonoaudiólogo pode e deve } \\
\text { contribuir para a formação } \\
\text { continuada de professo-res dos } \\
\text { sistemas de educação regular e } \\
\text { especial,de modo que a Escola } \\
\text { possa ser compreendida como um } \\
\text { espaço onde todos os que nela se } \\
\text { inse-rem têm um potencial e um } \\
\text { papel a desenvolver. Assim, } \\
\text { incluir alunos com necessidades } \\
\text { especiais deixa de ser visto como } \\
\text { resultado de prática espe-cífica ou } \\
\text { atendimento individualizado } \\
\text { somente; ao contrário, passa a ser } \\
\text { meta daqueles que acredi-tam que } \\
\text { todos os alunos têm limites que } \\
\text { devem ser respeitados. }\end{array}$ \\
\hline
\end{tabular}

Fonte: Autor (2020)

Conforme se evidencia pela presente pesquisa bibliográfica, foram identificados diversos benefícios e contribuições dos profissionais da fonoaudiologia em prol do processo de inclusão educacional de alunos da rede regular de ensino.

Dentre os benefícios evidenciados ressalta-se a possibilidade de uma maior socialização dos alunos e, consequentemente uma melhoria significativa na qualidade de vida de alunos que necessitam de uma atenção mais especial.

Ainda foi possível evidenciar o fato de os profissionais de fonoaudiologia possuírem a competência de proporcionar aos alunos com necessidades especiais o desenvolvimento da linguagem oral e escrita, da motricidade orofacial, da voz e de aspectos relacionados com a audição, mostrando aos responsáveis pelo processo educacional as principais dificuldades dos alunos, e desse modo, orientando o corpo docente, ou seja, sendo um verdadeiro auxiliar da equipe da escola, familiares, além 
de participar da elaboração e da manutenção de programas educacionais direcionados a inclusão de alunos com necessidades especiais.

Como agravante, temos o fato de que essa dificuldade não se restringe àqueles alunos que apresentam problemas de aprendizagem em virtude de algum tipo de déficit funcional, como é o caso dos distúrbios de aprendizagem, ou que estão participando de programas de inclusão ou de educação especial por apresentarem quadros de autismo, deficiência intelectual, deficiência auditiva, visual, motora, ou outros transtornos do desenvolvimento. A dificuldade é generalizada e nos leva a pensar que se já é difícil ensinar quem não tem problemas para aprender, o que dizer em relação àqueles alunos que necessitam de atenção e de recursos diferenciados para poderem se desenvolver em sua trajetória acadêmica? Podemos afirmar que propostas adequadas de ensino podem beneficiar todos os alunos, especialmente aqueles que de fato apresentam limitações ou dificuldade.

\section{Considerações Finais}

Por meio da presente pesquisa foi possível constatar a grande contribuição dos profissionais da fonoaudiologia em prol do processo de inclusão de alunos com necessidades especiais na educação regular de ensino.

Dentre as contribuições da fonoaudiologia no ambiente escolar em prol de uma maior inclusão de alunos com necessidades especiais ressaltam-se a identificação de estudantes que possuem dificuldades na comunicação e que sofrem com problemas de comunicação, e consequentemente resultando em problemas referentes a socialização, informando desse modo os professores sobre o modo de lidarem com esse corpo discente em sala de aula. Além da elaboração de programas e políticas pedagógicas direcionadas ao atendimento de forma individual, conforme a necessidade de cada aluno, não sendo concebido que os alunos sejam formados por um grupo homogêneo, sem levar em consideração a realidade de cada um.

Por meio da fonoaudiologia é capaz de haver um maior desenvolvimento das diversas modalidades de linguagem, em especial a oral e a escrita, além de contribuir em prol da motricidade orofacial, de aspectos referentes a voz e da audição, sendo os fonoaudiólogos auxiliares diretos dos responsáveis pelo processo de ensino aprendizagem e contribuindo com as dificuldades enfrentadas pelos familiares dos discentes que possuem dificuldades de comunicação.

Constatou-se ainda por meio da revisão bibliográfica analisada que as fontes de pesquisa referente a temática se encontram ainda bastante escassa no que se refere aos métodos da fonoaudiologia para uma forma de inclusão de alunos com necessidades especiais, havendo bastante teoria, mas sem grandes demonstrações de ações práticas de profissionais de fonoaudiologia no ambiente escolar, necessitando, desse modo a necessidade de pesquisas de campo sobre o referido assunto.

Salienta-se que a pesquisa é pertinente podendo servir de bases para futuros estudos sobre a contribuição dos profissionais da fonoaudiologia no processo de ensino-aprendizagem, proporcionando uma maior dignidade e uma maior igualdade para alunos que necessitam de uma maior atenção no ambiente da escola regular e não serem tratados como pessoas doentes que precisam de tratamento clínico, mas sim havendo um contínuo processo de despatologização desses seres humanos.

\section{Referências}

Alves, L. M. (2013). A Fonoaudiologia na relação entre escolas regulares de ensino fundamental e escolas de educação especial no processo de inclusão. Revista Brasileira de Educação Especial, São Bernardo do Campo, 18(8), 233-239.

Lei de Diretrizes e Bases da Educação Nacional LDB. 9394/1996.

Ministério da Educação. (2009). Resolução CNE/CEB 4/2009. Institui Diretrizes Operacionais para o Atendimento Educacional Especializado na Educação Básica, modalidade Educação Especial.

Diretrizes Nacionais para a Educação Especial na Educação Básica. (Resolução CNE/CEB nº 2/2001). 
Ministério da Educação. (2010). Base Nacional Comum Curricular, 2a versãorevista: http://basenacionalcomum.mec.gov.br/images/relatorios-analiticos/bncc2versao.revista.pdf.

Lei n 4.024, de 20 de dezembro de 1961. Fixa as Diretrizes e Bases da Educação Nacional.Diário Oficial da União: Brasília DF, 1961.

Lei n ${ }^{\circ}$ 5.692, de 11 de agosto de 1971. Fixa Diretrizes e Bases para o ensino de $1^{\circ}$ e $2^{\circ}$ graus, e dá outras providências.Diário Oficial da União: Brasília DF, 1971.

Constituição da República Federativa do Brasil de 1988. Diário Oficial da União: Brasília DF, 1988.

Lei no 8.069, de 13 de julho de 1990. Dispõe sobre o Estatuto da Criança e do Adolescente e dá outras providências.Diário Oficial da União: Brasília DF, 1990 .

Lei n ${ }^{\circ}$ 9.394, de 20 de dezembro de 1996. Estabelece as diretrizes e bases da educação nacional.Diário Oficial da União: Brasília DF, 1996.

Lei $n^{\circ} 7.853$, de 24 de outubro de 1989. Dispõe sobre o apoio às pessoas portadoras de deficiência, sua integração social, sobre a Coordenadoria Nacional pela Integração da Pessoa Portadora de Deficiência - Corde. Institui a tutela jurisdicional de interesses coletivos ou difusos dessas pessoas, disciplina a atuação do Ministério Público, define crimes e dá outras providências. Diário Oficial da União: Brasília DF, 1989.

Ministério da Educação. Resolução CNE/CEB n 02, de 11 de setembro de 2001. Institui Diretrizes Nacionais para a Educação Especial na Educação :Básica. http://portal.mec.gov.br/cne/arquivos/pdf/CEB0201.pdf.

Lei nº10.172, de 9 de janeiro de 2001. Aprova o Plano Nacional de Educação e dá outras providências. Diário Oficial da União: Brasília DF, 2001.

Decreto $n^{\circ} 3.956$, de 8 de outubro de 2001. Promulga a Convenção Interamericana para a Eliminação de Todas as Formas de Discriminação contra as Pessoas Portadoras de Deficiência.Diário Oficial da União: Brasília DF, 2001.

Ministério da Educação. Conselho Nacional de Educação. Conselho Pleno. Resolução CNE/CP nº 01 , de 18 de fevereiro de 2002. Institui Diretrizes Curriculares Nacionais para a Formação de Professores da Educação Básica em nível superior, curso de licenciatura, de graduação plena: http://portal.mec.gov.br/cne/arquivos/pdf/rcp01_02.pdf.

Ministério da Educação. Conselho Nacional de Educação. Câmara de Educação Básica. Resolução no 4, de 2 de outubro de 2009. Institui Diretrizes Operacionais para o Atendimento Educacional Especializado na Educação Básica, modalidade Educação Especial: http://portal.mec.gov.br/dmdocuments/rceb004_09.pdf.

Lei n ${ }^{\circ} 12.764$, de 27 de dezembro de 2012. Institui a Política Nacional de Proteção dos Direitos da Pessoa com Transtorno do Espectro Autista,e altera o $3^{\circ}$ do art. 98 da Lei no 8.112, de 11 de dezembro de 1990. Diário Oficial da União: Brasília, DF, 2012.

Lei n ${ }^{\circ}$ 13.005, de 25 de junho de 2014. Aprova o Plano Nacional de Educação-PNE e dá outras providências. Diário Oficial da União: Brasília, DF.

Calheta, P. P. (2005). Fonoaudiologia e educação: sentidos do trabalho de assessoria a escolas públicas. Assessoria e Fonoaudiologia: perspectivas de ação. Rio de Janeiro.

Conselho Federal de Fonoaudiologia. Áreas de competência do fonoaudiólogo no Brasil. (8a ed.), Brasília: Anais, 2012.

Ferreira, L. P. (2011). Fonoaudiologia Escolar: as origens de uma proposta. O fonoaudiólogo e a escola. São Paulo: Plexus Editora.

Freire, P. (1997). Pedagogia da Autonomia: Saberes necessários à prática educativa. Rio de Janeiro: Paz e Terra.

Gertel, M. C. R. (2011). O fonoaudiólogo e a escola - reflexões acerca da inclusão escolar: estudo de caso. Rev. CEFAC: https://www.scielo.br/pdf/rcefac/v13n5/130-09.pdf.

Garcez, A. (2019). Psicologia e a Fonoaudiologia na Educação Inclusiva: Algumas Considerações Sobre as Interfaces no Processo Educacional. Artigo científico apresentado a Faculdade de Mauá. Universidade Federal de São Paulo - EPM.

Maia, S. M. (2011). Acolhimento e inclusão: da clínica ao acompanhamento escolar de um sujeito com Síndrome de Down. Revista Distúrbios da Comunicação, São Paulo, 26(8), 305-311.

Martons, G. A. H. (2012). Refletindo sobre a atuação do fonoaudiólogo junto à educação especial. Rev. Perspectivas atuais da Fonoaudiologia na escola. 4, (3a ed.), São Paulo: Plexus Editora.

Monteiro, A. P. H. (2014). Mudanças nas concepções do professor do ensino fundamental em relação à inclusão após a entrada de alunos com deficiência em sua classe. Revista Brasileira de Educação Especial, Marília,23(4), São Paulo.

Reis, K. A. (2012). A importância da Fonoaudiologia na Educação Especial. Revista Fono Atual, 34, 45.

Ribas, A. (2015). Atuação fonoaudiológica nas escolas. Fonoaudiologia e Educação: uma parceria necessária. Curitiba.

Rios, F. M. (2011). A contribuição da fonoaudiologia na educação inclusiva em escolas de educação infantil no municípiode Betim, MG. Rev. Brasileira de Educação. Especial. 49, 24.

Siqueira, I. B. (2012). O brincar na escola: a relação entre o lúdico e a mídia no universo infantil. Rev. Bras. Ciênc. Esporte, Florianópolis. 34(2), 313-326. 